Pathophysiology of Haemostasis and Thrombosis
Pathophysiol Haemost Thromb 2005;34:6-12

DOI: $\underline{10.1159 / 000088541}$
Received: April 18, 2005

Accepted after revision: July 19, 2005

\title{
Long-Term Prospective Study of Recurrent Venous Thromboembolism in Patients Younger than 50 Years
}

\author{
María-José García-Fuster ${ }^{a} \quad$ María-José Forner $^{a}$ Conrado Fernández ${ }^{a}$ \\ Joaquín Gil ${ }^{b}$ Amparo Vaya ${ }^{c}$ Luis Maldonado ${ }^{b}$ \\ ${ }^{a}$ Service of Internal Medicine and b ${ }^{b}$ Service of Radiology, Hospital Clínico Universitario, \\ ${ }^{\mathrm{c}}$ Thrombosis and Haemostasis Unit, Hospital La Fe, Valencia, Spain
}

\section{Key Words}

Deep venous thromboembolism · Recurrent thromboembolism • Antiphospholipid antibodies · Thrombosis risk factors - Congenital risk factors · Acquired risk factors $\cdot$ Thrombophilia

\begin{abstract}
Long-term incidence of recurrent venous thromboembolism (VTE) in patients younger than 50 years, not affected by a malignancy or chronic diseases, are poorly characterized. After the initial episode of VTE and cessation of oral anticoagulation, 98 patients, mean age $32.2 \pm 9.2$ years were followed for a median of 117 months (range 6-165). Congenital risk factors for VTE were present in $36 \%$ of patients, acquired persistent (positive antiphospholipid antibodies during the whole follow-up) in 19\%, and acquired transitory in $44 \%$. Thirty episodes of recurrent VTE were documented. The cumulative incidence of VTE after 1 year of follow-up was 5.1\%, 9.8\% after 2 years, $14 \%$ after 4 years, and $34.2 \%$ after 8 years. In the univariate analysis, the relative risk of recurrent VTE was 2.66 [95\% confidence interval (Cl) 1.03-6.90] for congenital risk factors, $4.97(95 \% \mathrm{Cl} 1.75-14.0)$ for persistent acquired (antiphospholipid antibodies), 2.64 (95\% Cl 1.23$5.66)$ for male gender and $2.27(1.00-5.15)$ for body mass
\end{abstract}

index $>30 \mathrm{~kg} / \mathrm{m}^{2}$. In the multivariate analysis, male gender [hazard ratio (HR) $4.23,95 \% \mathrm{Cl} 1.88-9.77$ ) the presence of congenital factors ( $\mathrm{HR} 3.28,95 \% \mathrm{Cl} 1.25-8.63$ ) and acquired persistent factors (HR $8.50,95 \% \mathrm{Cl} 2.84$ 25.50) were independent risk factors for recurrent VTE. In patients under 50 years of age without malignancy or underlying chronic disease, hospitalized for an acute thromboembolic event, the presence of antiphospholipid antibodies, congenital defects of coagulation, male sex, and obesity were risk factors for recurrent VTE. These data raise the possibility that selected patients with VTE may require prolonged anticoagulation to prevent recurrent disease.

Copyright $(2005$ S. Karger AG, Basel

\section{Introduction}

Venous thromboembolic disease encompasses a variety of clinical presentations from hemodynamic instability and functional disability during the initial event to severe long-term sequelae and complications, including postthrombotic syndrome and recurrent venous thromboembolism (VTE). Chronicity of the disease is associated with a significant economic burden and a detrimental impact on quality of life [1-4]. Several clinical studies

\section{KARGER}

Fax +4161306 1234 E-Mail karger@karger.ch www.karger.com
(C) 2005 S. Karger AG, Basel

1424-8832/05/0341-0006\$22.00/0

Accessible online at: www.karger.com/pht
María-José García-Fuster, MD

Service of Internal Medicine, Hospital Clínico Universitario

Avda. Blasco Ibáñez 10

ES-46010 Valencia (Spain)

Tel./Fax +34 96 3862647, E-Mail garciafuster_mjo@gva.es 
have investigated risk factors for recurrent VTE in an attempt to stratify patients into higher- and lower-risk categories for recurrence and, if possible, to optimize their treatment for secondary prophylaxis [5]. It has been demonstrated that the presence of cancer, persistent thrombophilic conditions, advanced age, and short duration of anticoagulation after the first episode are associated with an increased risk of recurrent VTE [6-9]. So far, the populations investigated were heterogeneous, and there are few studies on the long-term clinical course of deep venous thrombosis (DVT) [6, 8-13]. Therefore, the objective of this prospective study was to determine the longterm incidence of recurrent VTE and the risk factors of thromboembolic disease in a homogeneous group of young patients under 50 years of age, not affected by malignancy or chronic diseases.

\section{Patients and Methods}

Between January 1, 1989, and November, 2004, 975 adult patients with acute venous thromboembolic disease were consecutively admitted to the Service of Internal Medicine of Hospital Clínico Universitario in Valencia, Spain. Patients 50 years of age or younger who required hospitalization due to thromboembolic disease were eligible for inclusion into a prospective, unicenter, follow-up study if they were not pregnant or affected by malignant disease or underlying chronic illnesses and were geographically accessible for follow-up. The institutional review board approved the study protocol, and each patient provided written informed consent.

The diagnosis of VTE, treatment and follow-up of the patients were made prospectively by the same team of physicians according to a preestablished protocol. DVT was diagnosed morphologically by echo-Doppler and ascending phlebography, and pulmonary embolism (PE) was diagnosed by spiral computed tomography or lung gammagraphy. Patients undergoing fibrinolysis had a previous transthoracic echocardiogram with measurement of the pulmonary artery pressure.

After a definite diagnosis of VTE had been established, all patients were treated with an initial course of high-dose intravenous standard heparin (a bolus of 5,000 U was followed by a continuous infusion of 30,000 per day, with the dose subsequently adjusted to maintain an activated partial thromboplastin time between 2.0 and 3.0 times the control value) or subcutaneous low-molecular-weight heparin (doses according to body weight). Therapy with oral anticoagulant agents (dicoumarol) was started 2 days later; the target international normalized ratio was 2.0-3.0. Treatment of confirmed PE in subjects with hemodynamic instability included thrombolysis with recombinant tissue-type plasminogen activator (rt-PA) on admission to the hospital, followed by anticoagulation. Oral anticoagulant treatment was continued for 6 months. Patients with DVT of the legs were instructed to wear graduated-compression stockings (providing $40 \mathrm{~mm} \mathrm{Hg}$ of pressure at the ankle) for at least 2 years.
We adopted Rosendaal's [14] classification of VTE based on the existence of congenital thrombotic or acquired risk factors.

The congenital risk factors studied are: antithrombin, protein $\mathrm{C}$ and protein $\mathrm{S}$ deficiency, presence of factor $\mathrm{V}$ Leiden and prothrombin G20210A, and were assessed after anticoagulation withdrawal.

Acquired factors were classified in: acquired persistent factors that included permanent antiphospholipid antibodies [anticardiolipin antibody (ACLA) and lupus anticoagulant (LAC)] and $a c$ quired transitory factors, i.e. oral contraceptives, a history of surgery or immobilization.

The existence of an antiphospholipid syndrome was diagnosed following the criteria of Levine et al.[15], defined as the clinical association of antiphospholipid antibodies and a hypercoagulability syndrome. The antiphospholipid antibodies are ACLA and/or LAC, and they must be detected in the blood on two or more occasions, at least 6 weeks apart.

The laboratory investigations included D dimer testing, blood cell count, standard biochemical tests, lipid profile, antinuclear antibodies, and tumor markers, including carcinoembryonic antigen, CA 19.9, CA 12.5, CA 15.3, and prostate-specific antigen levels. Laboratory assays with normal reference values and the risk factors evaluated were fully described in a previous study [16].

Follow-up was performed prospectively every 6 months after discontinuation of anticoagulation during the first 2 years and then yearly for up to 14 years. For patients who developed complications of anticoagulant treatment or who died during follow-up, the date, type of complication, and the cause of death were documented. Patients were instructed to notify the hospital of any new clinical event. Patients who failed to attend scheduled visits were contacted by telephone.

Since the study was designed to evaluate clinically relevant recurrent thromboembolic events, no surveillance for asymptomatic thrombosis was undertaken. Clinical events that had occurred since the previous visit were evaluated at each visit. Diagnostic studies were performed in clinically suspicious cases. Diagnosis of recurrent DVT was based on the presence of a new filling defect or the lack of visualization of a vein or a vein segment on venography, or on noncompressibility of a previous normal venous segment or enlargement of $\geq 4 \mathrm{~mm}$ of thrombus thickness on venous ultrasound compared with the previous studies [17]. Patients who received fibrinolysis had a new transthoracic echocardiogram with measurement of the pulmonary artery pressure. Patients thought to have PE underwent lung scanning, spiral CT, and echo-Doppler of the lower limbs. Major hemorrhage was defined as any bleeding episode that led to hospitalization or transfusion.

\section{Statistical Analysis}

Data are expressed as mean and standard deviation (SD). Differences between groups were assessed with the analysis of variance for continuous variables and the $\chi^{2}$ test for categorical variables. The cumulative incidence of recurrent thromboembolic events was calculated according to the method of Kaplan and Meier. Risk factors for recurrent VTE, including gender; body mass index (categorized as $<30$ and $>30 \mathrm{~kg} / \mathrm{m}^{2}$ ); etiopathogenesis of the thromboembolic event: congenital and acquired (persistent or transitory); and site of DVT: popliteal or ileofemoral, were evaluated with the use of univariate and multivariate Cox regression analysis including variables with an univariate level of significance less than 0.1 . p < 0.05 was considered to indicate statistical significance. 
Table 1. Characteristics of 98 patients with acute venous thromboembolism

\begin{tabular}{|c|c|c|c|}
\hline & All & Men & Women \\
\hline Patients & 98 & 50 & 48 \\
\hline Age, mean $\pm \mathrm{SD}$ & $32.2 \pm 9.2$ & $32.2 \pm 9.2$ & $32.3 \pm 9.2$ \\
\hline \multicolumn{4}{|l|}{ Body mass index, $\mathrm{kg} / \mathrm{m}^{2}$} \\
\hline$<30$ & 80 & 38 & 42 \\
\hline$>30$ & 18 & 12 & 6 \\
\hline \multicolumn{4}{|l|}{ Site of DVT } \\
\hline Lower extremities & 88 & 46 & 42 \\
\hline Popliteal and calf veins & 15 & 6 & 9 \\
\hline Femoral and ileal veins & 73 & 40 & 33 \\
\hline Upper extremities & 7 & 4 & 3 \\
\hline Pulmonary embolism with/without DVT & $23 / 3$ & $17 / 1$ & $6 / 2$ \\
\hline \multicolumn{4}{|l|}{ Risk factors } \\
\hline Congenital & 36 & 17 & 19 \\
\hline Factor V Leiden & 14 & 6 & 8 \\
\hline Prothrombin G20210A & 12 & 6 & 6 \\
\hline Protein $\mathrm{C}$ deficiency & 11 & 5 & 6 \\
\hline Protein S deficiency & 3 & 1 & 2 \\
\hline Acquired persistent & 62 & 33 & 29 \\
\hline Antiphospholipid antibodies & 19 & 8 & 11 \\
\hline Acquired transitory & 43 & 25 & 18 \\
\hline Immobilization & 25 & 16 & 9 \\
\hline Surgery & 8 & 4 & 4 \\
\hline Oral contraceptives & 10 & 0 & 10 \\
\hline \multicolumn{4}{|l|}{ Treatment } \\
\hline Anticoagulation 6 months & 98 & 50 & 48 \\
\hline Fibrinolysis and anticoagulation & 13 & 10 & 3 \\
\hline Vena cava filter, permanent & 3 & 2 & 1 \\
\hline Vena cava filter, removable & 4 & 1 & 3 \\
\hline
\end{tabular}

\section{Results}

Of the 975 consecutive patients with acute VTE, 832 were older than 50 years and were excluded. Of the remaining 143 patients, 25 were excluded because they had an active cancer or renal or liver dysfunction and 20 because they lived too far from the study center to be followed prospectively. Therefore, the study population included 50 men and 48 women with a mean \pm SD age of $32.2 \pm 9.2$ years. The demographic and clinical characteristics of the study patients are presented in table 1 . Thrombi were located in the lower extremities in 88 and in the upper extremities in 7. Leg DVT were limited to the popliteal or calf veins in $15.9 \%$, and $81.8 \%$ DVT affected the femoral or iliac veins. Twenty-six patients were found to have PE, both PE and DVT in 23 and isolated PE in 3. Thirteen patients with PE were treated with rt-PA. Vena cava filters were inserted in 7 patients, removable in 4 patient, prior to fibrinolysis, and permanent in 3 patients.
Thirty-six patients $(36 \%)$ had congenital risk factors (factor V Leiden, $\mathrm{n}=14$; prothrombin G20210A, $\mathrm{n}=12$; protein $\mathrm{C}$ deficiency, $\mathrm{n}=11$; and protein $\mathrm{S}$ deficiency, $\mathrm{n}=3)$ and $19(19 \%)$ had antiphospholipid antibodies, and all of them fulfilled the criteria of antiphospholipid syndrome. In the remaining 43 (44\%) patients only acquired transitory factors were demonstrated.

After the cessation of oral anticoagulant treatment patients were followed for a median of 117 months (range 6-165 months). Forty-six percent of patients completed 5 years of follow-up and $23 \%$ completed 8 years of followup. No patient was lost to follow-up. Of the 98 patients, one patient with antiphospholipid antibodies died at 6 years from a cause unrelated to VTE and in another patient, a diagnosis of cancer was made at 7 years. Gastrointestinal bleeding episodes occurred in 3 patients. None of these events were fatal.

Thirty episodes of recurrent VTE during follow-up were documented (incidence rate 5.8 per 100 person- 
Fig. 1. a Cumulative probability of recurrent venous thromboembolism after anticoagulation withdrawal by etiologic group. b Cumulative probability of recurrent venous thromboembolism after anticoagulation withdrawal by sex group (see text). c Cumulative probability of recurrent venous thromboembolism after anticoagulation withdrawal by body mass index).
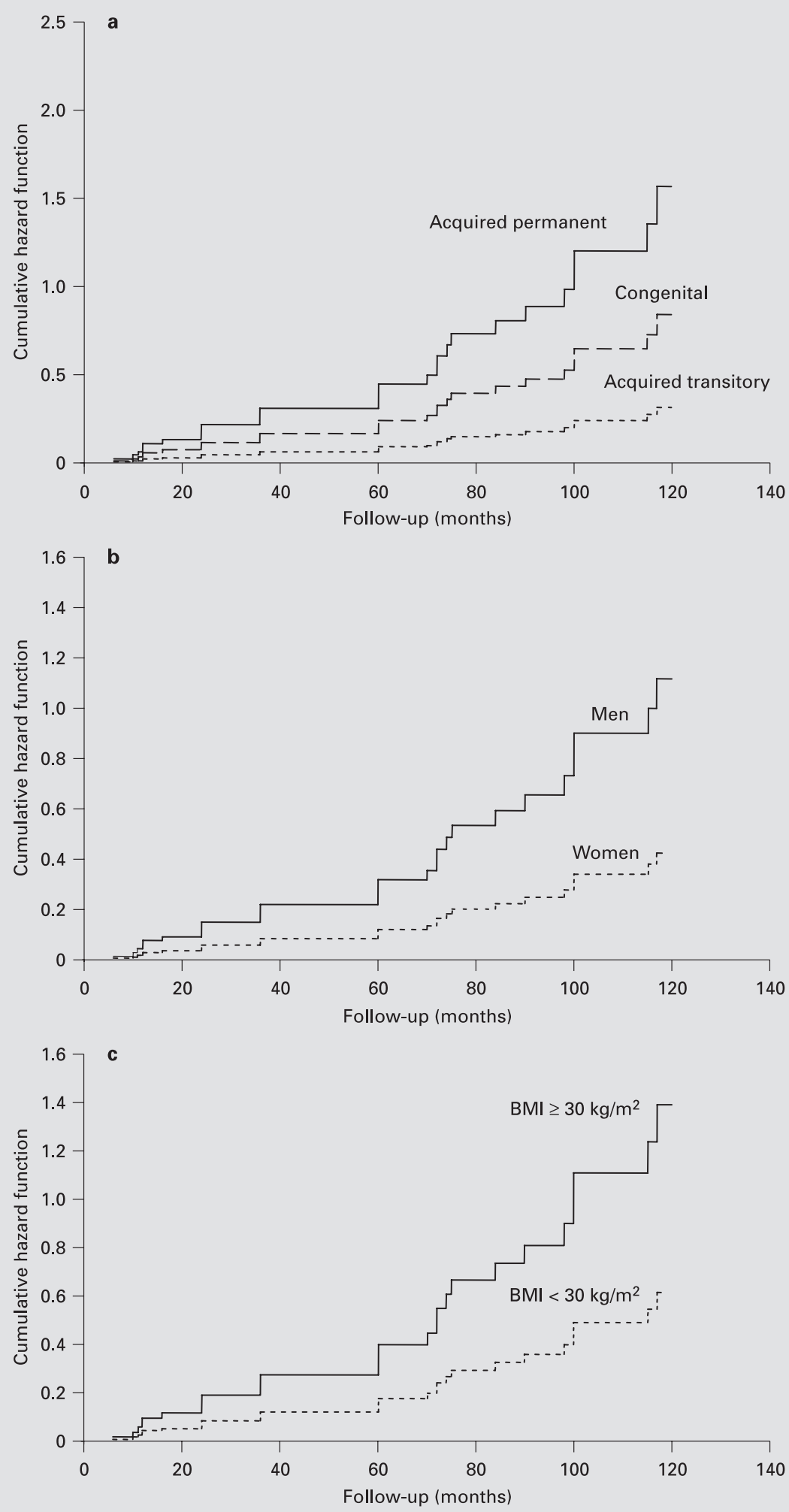
Table 2. Risk factors for recurrent venous thromboembolism: results of univariate and multivariate Cox regression analysis

\begin{tabular}{|c|c|c|c|c|}
\hline \multirow[t]{2}{*}{ Variables } & \multicolumn{2}{|c|}{ Univariate analysis } & \multicolumn{2}{|c|}{ Multivariate analysis } \\
\hline & risk ratio & $95 \% \mathrm{CI}$ & risk ratio & $95 \% \mathrm{CI}$ \\
\hline \multicolumn{5}{|l|}{ Risk factors } \\
\hline Acquired transitory & 1 & & 1 & \\
\hline Congenital & 2.66 & $1.03-6.9$ & 3.28 & $1.25-8.63$ \\
\hline $\begin{array}{l}\text { Acquired persistent } \\
\text { (antiphospholipid antibodies) }\end{array}$ & 4.97 & $1.75-14.0$ & 8.5 & $2.84-25.5$ \\
\hline Gender (male vs. female) & 2.64 & $1.23-5.66$ & 4.23 & $1.88-9.77$ \\
\hline \multicolumn{5}{|l|}{ Body mass index, $\mathrm{kg} / \mathrm{m}^{2}$} \\
\hline$<30$ & 1 & & & \\
\hline$>30$ & 2.27 & $1.0-5.15$ & 1.92 & $0.83-4.43$ \\
\hline Site of DVT (proximal vs. distal) & 1.42 & $0.49-4.13$ & & \\
\hline
\end{tabular}

year). Thrombi were located in the ipsilateral affected member in $72 \%$ of cases. Only 1 patient who just had PE was found to have recurrent PE. Control echocardiographic studies performed in the 13 patients treated with rt-PA showed normal values of the pulmonary artery pressure in all of them.

The cumulative incidence of recurrent VTE after 1 year of follow-up was 5.1\% [95\% confidence interval (CI) $4.4-9.2), 9.8 \%$ after 2 years (95\% CI 6.3-12.4\%), $14.0 \%$ after 4 years $(95 \%$ CI $10.4-18.5 \%)$, and $34.2 \%$ after 8 years $(95 \%$ CI $28.2-40.1 \%)$. In the univariate analysis, the relative risk of recurrent VTE was $2.66(95 \%$ CI 1.03-6.90) for congenital risk factors, 4.97 (95\% CI 1.75-14.0) for persistent acquired factors (antiphospholipid antibodies), 2.64 (95\% CI 1.23-5.66) for male gender, and $2.27(1.00-5.15)$ for BMI $>30$. No statistically significant associations were found between the initial side of DVT (proximal or distal) and recurrence of VTE (table 2). In the multivariate analysis, male gender [hazard ratio (HR) $4.23,95 \%$ CI 1.88-9.77], presence of congenital factors (HR 3.28, 95\% CI 1.25-8.63), presence of acquired persistent factors (HR 8.50, 95\% CI 2.8425.50) were independent risk factors for recurrent VTE (table 2, fig. 1).

\section{Discussion}

The present study was performed in a cohort of young patients hospitalized for VTE and shows that the possibility of recurrent thromboembolic disease after the initial episode is never negligible, and that the presence of antiphospholipid antibodies, congenital factors, male sex, and obesity increases the risk of recurrence of VTE.
The study population included young adults, under 50 years of age, not affected by malignant disease or chronic illnesses, in order to avoid the effect of age (the incidence of first-time plus recurrent VTE rises with age) and of these underlying pathological conditions on VTE recurrence. The characteristics of the present cohort are different from those previously reported by others in terms of age range and absence of malignancies or chronic diseases. To date, one or more underlying causes of VTE can be found in the majority of patients with the disease. Therefore the Rosendaal's classification [14] of VTE, based on the existence of congenital or acquired risk factors, seems to be more appropiate than the previous classification of VTE based on idiopathic or secondary factors [9].

In the study of Prandoni et al. [11], the ages of the patients ranged between 29 and 83 years, in the study of Hansson et al. [12] between 17 and 95 years, and in the study of Heit et al. [8] the mean age was $61.7 \pm 24$ years. Moreover, patients with malignant disease or other conditions that may be associated with an increased risk for VTE recurrence were included in their study cohorts. On the other hand, another consequence of the selection of the study subjects is a lower number of losses to follow-up related to severity of disease. Patients were randomly distributed by gender ( 50 men, 48 women) despite the fact that fertile women are exposed to more risk factors than men [14]. Other characteristics of the present cohort are that during oral anticoagulation, which was maintained for 6 months, the rate of major bleeding of 3\% is similar to that reported in other studies $[18,19]$. None of the patients with PE receiving rt-PA had complications or developed pulmonary hypertension, which is in favor of the use of fibrinolysis when this treatment option is not contraindicated [20]. 
In our prospective cohort study, the cumulative incidence of recurrent VTE was 5\% after 1 year, 19\% after 2 years, and $34 \%$ after 8 years. These findings are consistent with other studies, including $7.0 \%$ at 1 year and $22.0 \%$ at 5 years in the study of Hansson et al. [12], 17.5\% at 2 years and $30.3 \%$ at 8 years in the study of Prandoni et al. [11] and $12.9 \%$ after 1 year and $30.4 \%$ after 10 years in the population-based cohort study of Heit et al. [8]. These variations may reflect differences in the characteristics of the study populations.

Ninety-five percent of patients with recurrent VTE presented a new episode of thrombosis, in $72 \%$ of cases in the same extremity, probably because of residual venous thrombosis $[12,21]$.

With regard to the relationship between the etiopathogenesis of the initial VTE episode and the recurrent thromboembolic event, patients with antiphospholipid antibodies had the highest risk for recurrence, followed by patients with congenital coagulation defects and those with only acquired transitory risk factors. These results are in agreement with prospective studies that have shown an association between antiphospholipid antibodies [14, $22,23]$ or hereditary thrombophilia [7, 24, 25] and venous thrombosis, although the influence of these risk factors for recurrent VTE in a cohort of young patients with a prolonged follow-up has not been previously assessed.

The effect of sex on the risk for recurrent VTE is unclear. No consistent differences in the incidence of recurrent thromboembolic events among men and women were found in some studies [9, 26], whereas among patients $>65$ years, Kniffin et al. [27] reported that women had a higher relative risk of DVT. In our study, as in oth- ers $[8,28]$, male gender was an independent variable significantly associated with recurrent VTE.

The importance of obesity as a risk factor for VTE was recently stressed in a large case-control study in which the authors found that obese individuals had higher levels of factor VIII and factor IX [29]. The importance of obesity, however, has not been tested as a determinant factor for the recurrence of VTE. In the present study, obesity was also related to the recurrence of VTE. The impact, however, was diluted when it was included with other risk factors, probably because of the high influence of the other risk factors and of the young age of the population.

In summary, in a prospective follow-up study of young patients without malignancy or underlying chronic disease hospitalized for an acute thromboembolic event, the risk of recurrent VTE is never negligible. In this study cohort, the presence of antiphospholipid antibodies, congenital defects of coagulation, male sex, and obesity were risk factors for recurrent VTE. These data raise the possibility that selected patients with VTE may require prolonged anticoagulation to prevent recurrent disease. Recent promising experiences with long-term, low-intensity warfarin therapy [30] or the novel oral direct thrombin inhibitor, ximelagatran [31], may offer a clinically meaningful reduction in the incidence of recurrent VTE in patients with risk factors.

\section{Acknowledgment}

We thank Marta Pulido, MD, for editing the manuscript and providing editorial assistance.

\section{References}

1 White RH: The epidemiology of venous thromboembolism. Circulation 2003;107:I-4-I-8.

2 Kearon C: Natural history of venous thromboembolism. Circulation 2003;107:I-22-I-30.

3 Lamping DL, Schroter S, Kurz X, et al: Evaluation of outcomes in chronic venous disorders of the leg: development of a scientifically rigorous, patient-reported measure of symptoms and quality of life. J Vasc Surg 2003;37:410 419.

-4 Kahn SR, Hirsch A, Shrier I: Effect of postthrombotic syndrome on health-related quality of life after deep venous thrombosis. Arch Intern Med 2002;27:1144-1148.

5 Palareti G, Cosmi B: Predicting the risk of recurrence of venous thromboembolism. Curr Opin Hematol 2004;11:192-197.
6 Schulman S, Rhedin AS, Lindmarker P, et al: A comparison of six weeks with six months of oral anticoagulant therapy after a first episode of venous thromboembolism. Duration of Anticoagulation Trial Study Group. N Engl J Med 1995;332:1661-1665.

7 Lindmarker P, Schulman S, Sten-Linder M, et al: The risk of recurrent venous thromboembolism in carriers and non-carriers of the G1691A allele in the coagulation factor $\mathrm{V}$ gene and the G20210A allele in the prothrombin gene. DURAC Trial Study Group. Duration of Anticoagulation. Thromb Haemost 1999;81:684689.
-8 Heit JA, Mohr DN, Silverstein MD, et al: Predictors of recurrence after deep vein thrombosis and pulmonary embolism: a populationbased cohort study. Arch Intern Med 2000; 160:761-768.

9 Cushman M, Tsai A, Heckbert SR, et al: Incidence rates, case fatality, and recurrence rates of deep thrombosis and pulmonary embolus: the Longitudinal Investigation of Thromboembolism Etiology (LITE) (abstract). Thromb Haemost 2001;86(suppl 1): OC2349.

10 Arcelus JI, Caprini JA, Monreal M, et al: The management and outcome of acute venous thromboembolism: a prospective registry including 4,011 patients. J Vasc Surg 2003;38: 916-922. 
11 Prandoni P, Lensing AW, Cogo A, et al: The long-term clinical course of acute deep venous thrombosis. Ann Intern Med 1996;125:1-7.

- 12 Hansson PO, Sörbo J, Eriksson H: Recurrent venous thromboembolism after deep vein thrombosis: incidence and risk factors. Arch Intern Med 2000;160:769-774.

13 Patel RK, Ford E, Thumpston J, et al: Risk factors for venous thrombosis in the black population. Thromb Haemost 2003;90:835-838.

14 Prandoni P, Cogo A, Bernardi E, et al: A simple ultrasound approach for detection of recurrent proximal-vein thrombosis. Thromb Haemost 1993;88:1730-1735.

15 Levine JS, Branch DW, Rauch J: The antiphospholipid syndrome. N Engl J Med 2002; 346:752-763.

16 García-Fuster MJ, Fernández C, Forner MJ, et al: Risk factors and clinical characteristics at thromboembolic venous disease in young patients: a prospective study. Med Clin (Barc) 2004;123:217-219.

-17 Prandoni P, Cogo A, Bernardi E, et al: A simple ultrasound approach for detection of recurrent proximal-vein thrombosis. Thromb Haemost 1993;88:1730-1735.

18 White RH, Beyth RJ, Zhou H, et al: Major bleeding after hospitalization for deep-venous thrombosis. Am J Med 1999; 107:414-424.
19 Levine MN, Raskob G, Landefeld S, et al: Hemorrhagic complications of anticoagulant treatment. Chest 2001;119:S108-S121.

20 Pengo V, Lensing AWA, Prins MH, et al: Incidence of chronic thromboembolic pulmonary hypertension after pulmonary embolism. N Engl J Med 2004;350:2257-2264.

21 Prandoni P, Lensing AW, Prins MH, et al: Residual venous thrombosis as a predictive factor of recurrent venous thromboembolism. Ann Intern Med 2002;137:955-960.

22 Khamashta MA, Cuadrado MJ, Mujic F, et al: The management of thrombosis in the antiphospholipid-antibody syndrome. N Engl J Med 1995;332:993-997.

23 Schulman S, Svenungsson E, Granqvist S: Anticardiolipin antibodies predict early recurrence of thromboembolism and death among patients with venous thromboembolism following anticoagulant therapy. Duration of Anticoagulation Study Group. Am J Med 1998; 104:332-338

24 Ridker PM, Miletich JP, Stampfer MJ, et al: Factor V Leiden and risks of recurrent idiopathic venous thromboembolism. Circulation 1995;92:2800-2802.

25 Simioni P, Prandoni P, Lensing AW, et al: The risk of recurrent venous thromboembolism in patients with an Arg506 $\rightarrow$ Gln mutation in the gene for factor V (factor V Leiden). N Engl J Med 1997;336:399-403.
26 Anderson FA Jr, Wheeler HB, Goldberg RJ, et al: A population-based perspective of the hospital incidence and case-fatality rates of deep vein thrombosis and pulmonary embolism. The Worcester DVT Study. Arch Intern Med 1991;151:933-938.

-27 Kniffin WD Jr, Baron JA, Barrett J, et al: The epidemiology of diagnosed pulmonary embolism and deep venous thrombosis in the elderly. Arch Intern Med 1994;154:861-866.

28 Kyrle PA, Minar E, Bialonczyk C, et al: The risk of recurrent venous thromboembolism in men and women. N Engl J Med 2004;350: 2558-2563.

-29 Abdollahi M, Cushman M, Rosendaal FR: Obesity: risk of venous thrombosis and the interaction with coagulation factor levels and oral contraceptive use. Thromb Haemost 2003;89:493-498.

30 Ridker PM, Goldhaber SZ, Danielson E, et al: Long-term, low-intensity warfarin therapy for the prevention of recurrent venous thromboembolism. N Engl J Med 2003;348:14251434.

31 Schulman S, Wahlander K, Lundstrom T, et al: Secondary prevention of venous thromboembolism with the oral direct thrombin inhibitor ximelagatran. N Engl J Med 2003;349:17131721. 